\title{
Influence of the residual stresses induced by shot-peening on the oxidation of Zr plates
}

\author{
Virgil Optasanu ${ }^{1, a^{*}}$, Pierre Jacquinot ${ }^{1, b}$ and Tony Montesin ${ }^{1, c}$ \\ ${ }^{1}$ ICB UMR 6303 CNRS - Université de Bourgogne, 9 Av Alain Savary, BP. 47870, \\ 21078 Dijon Cedex, France address of first author, including country \\ avirgil.optasanu@u-bourgogne.fr, ${ }^{b}$ pierre.jacquinot@utt.fr, ${ }^{\mathrm{C}}$ tony.montesin@u-bourgogne.fr
}

Keywords: residual stress, shot-peening, high temperature oxidation, Zirconium, stress / diffusion coupling

\begin{abstract}
The present study evaluates the influence of the residual stress on the oxidation rate of $\mathrm{Zr}$ at $650^{\circ} \mathrm{C}$. It is shown that the oxidation rate can be substantially decreased by shot-peening. A systematic investigation of the various factors (such as the residual stress, the surface pollution and the chemical composition of the oxidation atmosphere) is realized to separate their influence on the oxidation. The influence of an annealing made after the shot-peening is also considered. One show that the pollution of the surface during the shot-peening process is not responsible for the oxidation rate decrease.
\end{abstract}

\section{Introduction}

The shot peening is one of the possible way to introduce high value residual stress and residual stress gradients by introducing strong plastic deformations on the superficial layers of the samples. Well known as a process used for fatigue life improvement, the influence of the shot peening on the corrosion is less investigated. The high residual stress values as well the very high stress gradients are susceptible to modify the diffusion of the oxygen and then influence the corrosion behavior of the material. In our previous works [1] we investigated the influence of the shot-peening on the corrosion for the Zirconium for short oxidation times $(30 \mathrm{~min})$ at high temperature $\left(650^{\circ} \mathrm{C}\right)$ and we noticed that the shot-peened samples have oxidation rates sensibly lower than the original material. The $\mathrm{Zr}$ have been used in this study because of the interest of the nuclear industry on the corrosion of this metal and because of the anionic nature of the oxidation at high temperature, with bulk diffusion of the $\mathrm{O}^{2-}$ ions. This last point allows us to couple the chemical diffusion of the oxygen to the residual stress. The main objective of this paper is to study the influence of the shot-peening on the oxidation by analyzing several factors: shot-peening duration, nature of the oxidant atmosphere, surface pollution and intensity of the stress values.

The high temperature oxidation $\left(>600^{\circ} \mathrm{C}\right)$ of Zirconium is governed by the bulk diffusion of $\mathrm{O}^{2-}$ ions into the metal lattice. The solubility of the oxygen in zirconium is very important $(29 \%$ atomic at $650^{\circ} \mathrm{C}$ ). At high temperature the diffusion coefficient has sufficiently large values to give large diffusion zones of several tens of microns. The insertion of the oxygen into the zirconium lattice tends to expand the metal lattice and then gives important compression stress values in the plane parallel to the oxide/metal interface.

The diffusion process is closely influenced by the mechanical stress [2,3,4]. As shown in the literature $[5,6]$ the apparent diffusion coefficient depends on the stress as well on the stress gradient and can influence the oxidation based on anionic diffusion of the oxygen into the metal lattice $[7,8,9]$. By using pure thermodynamic developments the First Fick's law can be modified as follows [1]:

$$
\vec{J}=-D_{0}\left[\left(1+\frac{M_{0}}{R T} \eta_{\mathrm{ii}} \sigma_{\mathrm{ii}}\right) \vec{\nabla} \mathrm{c}-\frac{\mathrm{M}_{0}}{\mathrm{RT}} \mathrm{c} \vec{\nabla}\left(\eta_{\mathrm{ii}} \sigma_{\mathrm{ii}}\right)\right],
$$

where $\vec{J}$ is the flux of oxygen, $M_{0}$ is the molar mass of the $\mathrm{Zr}, \mathrm{c}$ is the oxygen concentration, $\sigma_{i j}$ is the stress tensor and $\eta_{\mathrm{ij}}=\frac{\partial \varepsilon_{\mathrm{chem}}}{\partial \mathrm{c}}$ is the chemical expansion coefficient [2]. For the $\mathrm{Zr}$, the average value of the chemical expansion coefficient is $\eta=3.5510^{-5} \mathrm{~m}^{3} / \mathrm{kg}$. 
The Eq. (1) is purely thermodynamic and do not contains any phenomenological parameter. It shows two driving forces one governed by the gradient of the concentration but influenced by the mechanical stress, the other one governed by the gradient of the stress.

The influence of the stress on the term $-D_{0}\left(1+\frac{M_{0}}{R T} \eta_{i i} \sigma_{i i}\right) \vec{\nabla}$ c can be illustrated like this: for a material that expands when oxygen diffuses within its crystallographic lattice $(\eta>0)$ the flux increases when the material is tensioned and decreases when it is compressed. The presence of a compressive stress decreases the effective diffusion coefficient.

The terms $\mathrm{D}_{0} \frac{\mathrm{M}_{0}}{\mathrm{RT}} \mathrm{c} \vec{\nabla}\left(\eta_{\mathrm{ii}} \sigma_{\mathrm{ii}}\right)$ can be illustrated like a mechanic pump: oxygen migrates from compressed to less compressed regions. The stress gradient opposes to the concentration gradient.

The stress acts like a driving force. Since the stress is limited by the yield stress value, while the stress gradient can reach strong values, this term can be particularly influent on the oxygen flux. A compression stress will decrease the value of the apparent diffusion coefficient. As an example, a biaxial compression stress of about $600 \mathrm{MPa}$ applied on $\mathrm{Zr}$ decreases the effective diffusion coefficient of about $30 \%$ at $650^{\circ} \mathrm{C}$. While the stress value is limited by the mechanical properties of the material, the stress gradient can reach very strong values if the variation of the stress is made within a very short length. The term containing the stress gradient can then be very influent and can act in some cases as an up-wind driving force.

The stress taken into account can be due to external forces or to thermal and mechanical processes that the sample undergone [9]. In our previous simulation works we have shown that the diffusion can be "manipulated" by the mechanical stress

\section{Experimental procedure}

Commercially pure Zr plates ( $2 \mathrm{~mm}$ thick, 99,2\% purity, Goodfellow) have been used in this study. Rectangular samples $50 \times 25 \mathrm{~mm}^{2}$ were cut, annealed at $700^{\circ} \mathrm{C}$ for $2 \mathrm{~h}$ under dynamic secondary vacuum. The samples were then shot-peened for 10 or $30 \mathrm{~min}$ on each side, by alternate steps of $5 \mathrm{~min} / \mathrm{side}$ in order to avoid a too strong Almen's deformation. The shot-peening is realized using $20 \mathrm{~g}$ of $2 \mathrm{~mm}$ tungsten carbide balls and a sonotrode vibrating at $20 \mathrm{kHz}$ with an amplitude of $12 \mu \mathrm{m}$.

After shot-peening, small samples of $10 \times 10 \mathrm{~mm}^{2}$ were used for thermo-gravimetric analysis (TGA). Samples have been subjected to oxidation at $650^{\circ} \mathrm{C}$ for 3 days. During the high temperature exposure the grains of the metal do not grow. In contrast, the temperature is high enough to produce at least partially the dislocations recovery and then the residual stresses must decrease rapidly.

The residual stress has been measured by incremental hole-drilling method. Experimental details are presented in ref. [1]. Figure 1 shows the profile of the residual stress in a direction parallel to the sample surface with respect to the depth. The stress curve has a particular shape characteristic to shot-peening: there is a first region on the first $150 \mu \mathrm{m}$ with a negative gradient, followed by a zone with positive gradient. In the case of the oxidation, according to the Eq. (1), the first zone will contribute to decrease the oxygen flux into the metal bulk. Due to the positive stress gradient in the second zone $(>150 \mu \mathrm{m})$, the apparent diffusion coefficient value increases. The first zone slows the diffusion, while the second zone accelerates it.

\section{Results and discussion}

Influence of the shot-peening duration. In the early stages of the oxidation, the ratedetermining process is the diffusion. This produces parabolic mass gain profiles obtained in TGA as shown in Fig. 2. In the further stages (see Fig. 3 and Fig. 4), there is a competition between diffusion and cracking of the oxide layer which gives linear shapes of mass gain curves. In this linear behavior region the oxide layer thickness remains globally constant; cracking appears parallel to the interface oxide/metal at different locations. 


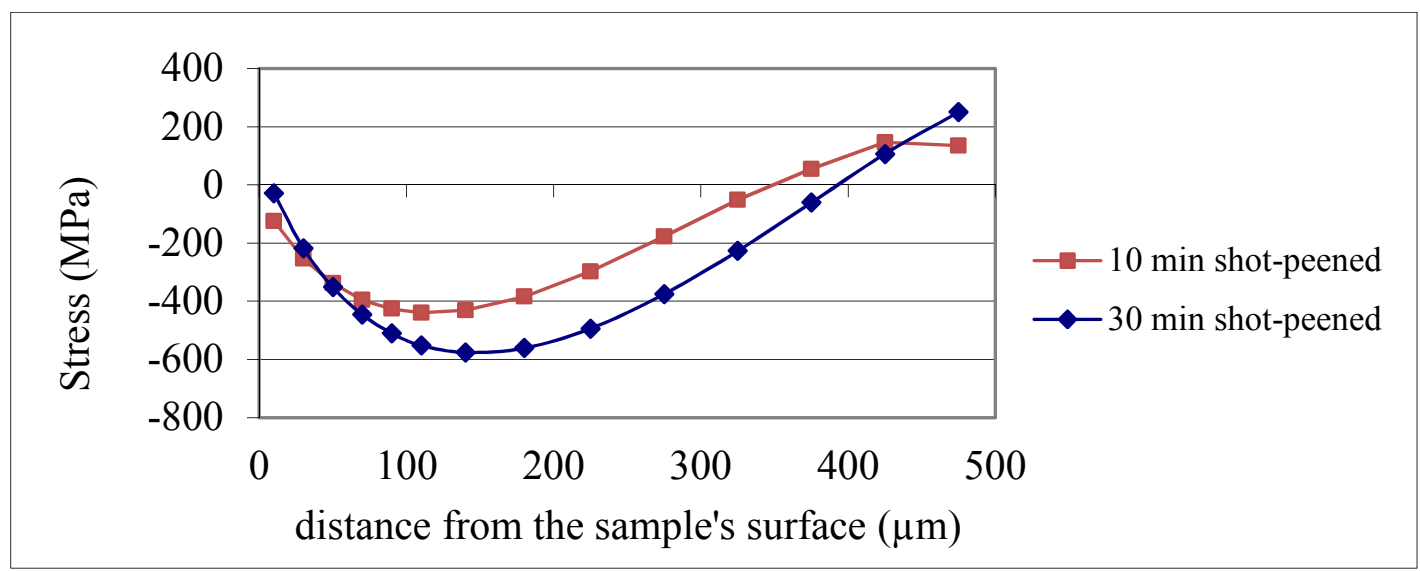

Figure 1. Residual stress after shot-peening

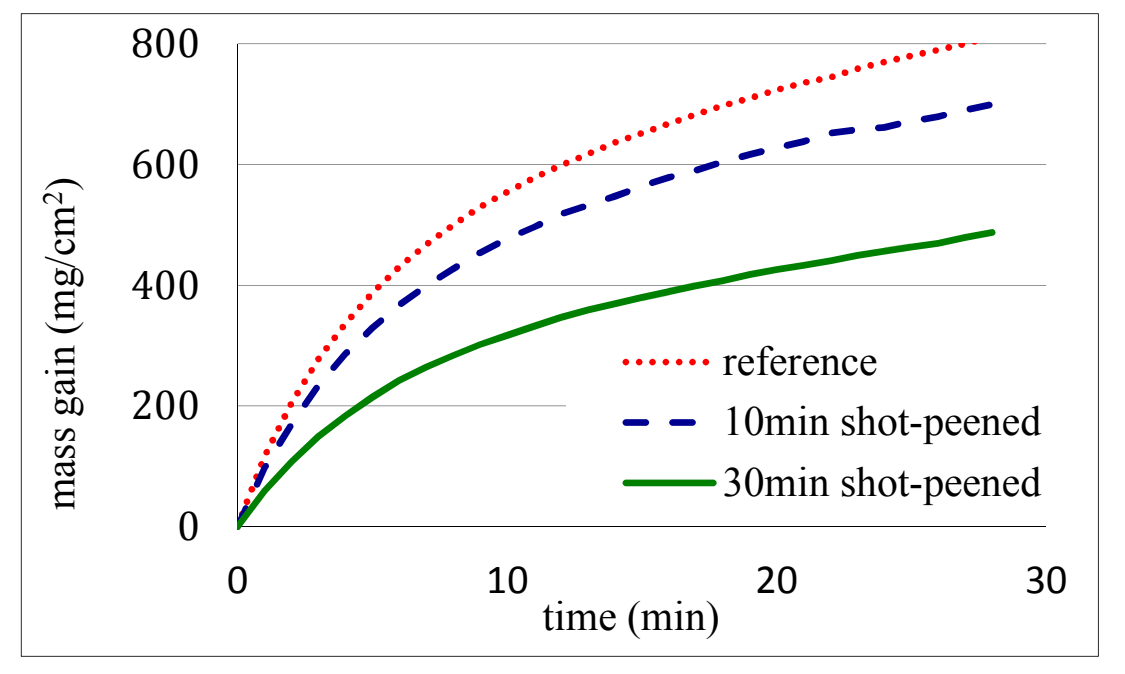

Figure 2. Mass gain of one-side shot-peened $\mathrm{Zr}$ samples during oxidation under 200 mbar oxygen at $650^{\circ} \mathrm{C}$. [9]

Influence of the chemical composition of the atmosphere. With the purpose of discriminate the effects of the azote present in the atmosphere, two types of oxidation have been made: under air at atmospheric pressure or under $200 \mathrm{mbar}$ of $\mathrm{O}_{2}$. The comparison shown in the figure below shows that the presence of the $\mathrm{N}_{2}$ from the atmosphere has no noticeable influence on the mass gain of the sample after 3 days of oxidation. Slight differences can however be noticed in the mass gain curve shape, especially the slope of the linear part.

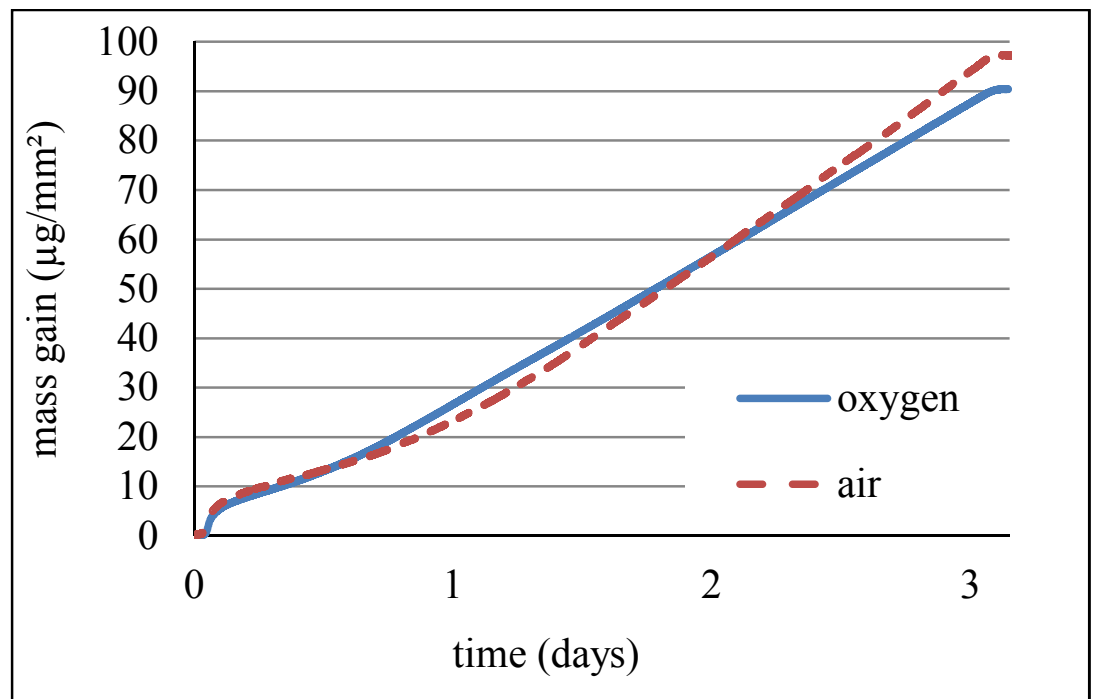

Figure 3. Influence of the atmosphere's composition on the oxidation 
Influence of stress-relief annealing. In order to evaluate the influence of the stress profile on the oxygen diffusion an annealing process at $700^{\circ} \mathrm{C}$ was applied to the samples after shot-peening for 2 or $6 \mathrm{~h}$. The annealing produces an annihilation of the stresses and a decrease of the density of dislocations. The figure below shows the influence of the annealing on the mass gain of $10 \mathrm{~min}$ shot-peened samples. The annealing of the shot-peened samples produces oxidation rates sensibly more important than the reference. For information we insert in this graph also the mass gain curve of a sample, which was neither shot-peened nor annealed. The annealing produces on the shotpeened samples a behavior close to the as received material. The micrographic analysis shows that there is no grain growth due to the annealing, thus the low rate of the oxidation of the 10 min shotpeened sample (called "reference" on the Fig. 4) is influenced only by the residual stress of the sample. As the stress is strongly reduced by the long exposure to high temperature, the stress can act a predominant role only in the first stages of the oxidation.

As seen on the mass gain graph the annealing seems to have a role on the linear part of the curves. One can deduce that the mechanical condition introduced by the shot-peening changes the characteristics of the oxide formed on the early stages of oxidation, which changes also the linear stage of the mass gain curve. This aspect will be studied in future works.
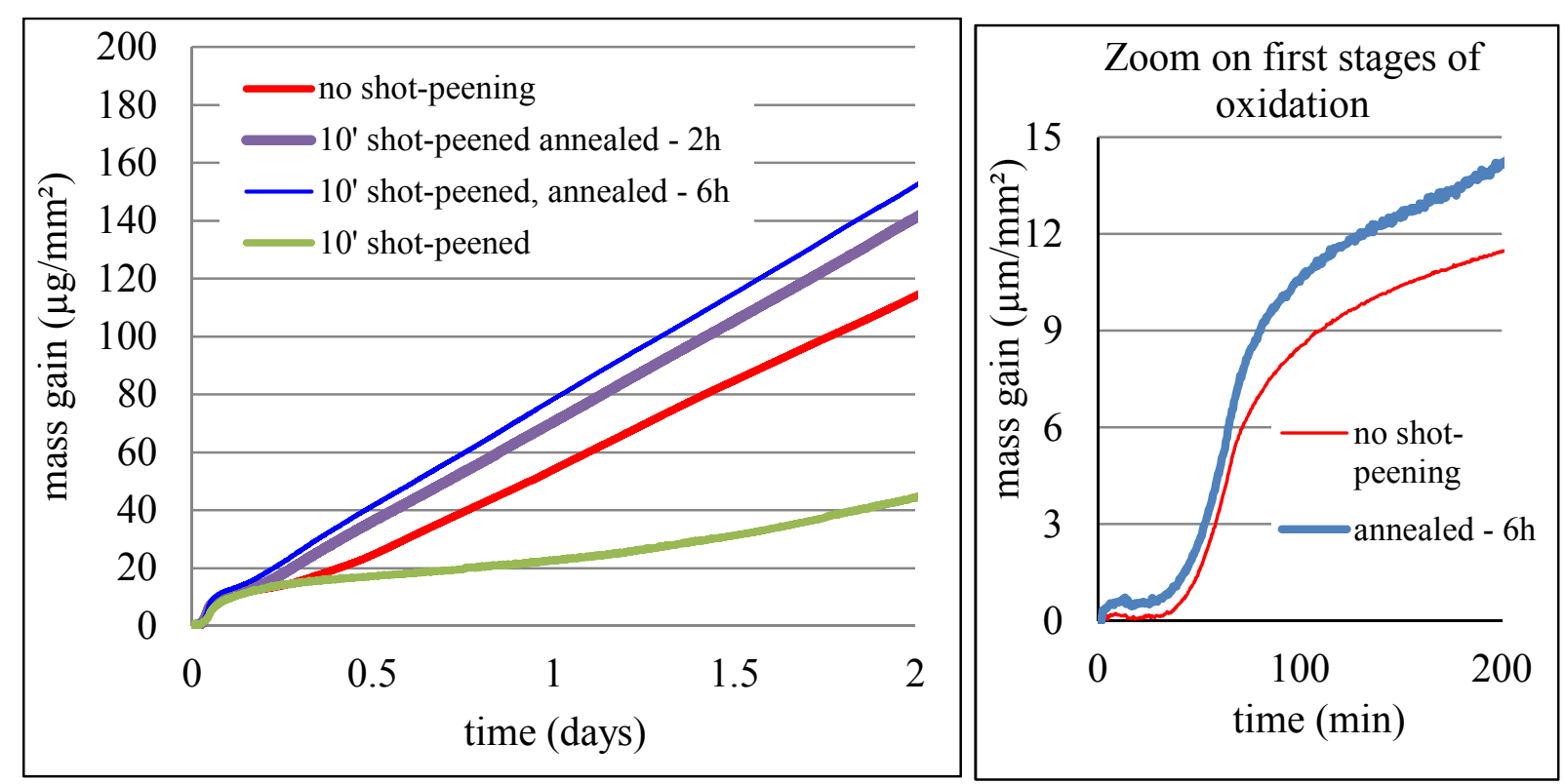

Figure 4. Influence of the annealing post shot-peening (10 min) on the mass gain.

Influence of the surface etching. As mentioned, the shape of the residual stress profile with respect to the depth has an influence on the chemical diffusion. We chose to take off the superficial layers of the sample by etching using a solution of $6 \% \mathrm{HF}+50 \% \mathrm{HNO}_{3}$. The samples are immersed in the solution for $15 \mathrm{~s}$. The etching removes the superficial stressed layers, which are eventually polluted by the shot-peening.

The etching removes the superficial few $\mu \mathrm{m}$ from the sample surface (about $3 \mu \mathrm{m}$ for $15 \mathrm{~s}$ of immersion into the solution) and takes off the natural thin protective layer of $\mathrm{ZrO}_{2}$. Moreover, the chemical reaction can differently affect the grain boundaries and hence increase the free surface of the sample, modifying the reactivity of the sample. The etching removes the superficial pollution that occurs during the shot-peening. This pollution can have as origin the balls material, or the chamber containing the balls. Figure 5 shows that the etching has no influence on the first stage of the oxidation $(<0.5$ days) but has a strong influence on the moment when the breakaway occurs. This result is a little surprising because the mass gain seems to be very similar in the first stage of the oxidation, when the diffusion governs the oxidation. It seems then that the protective layer of the compact oxide is thinner for the etched samples. Further investigations by SEM analysis will be done in order to qualify the cracking and the morphology of the oxide layer. 


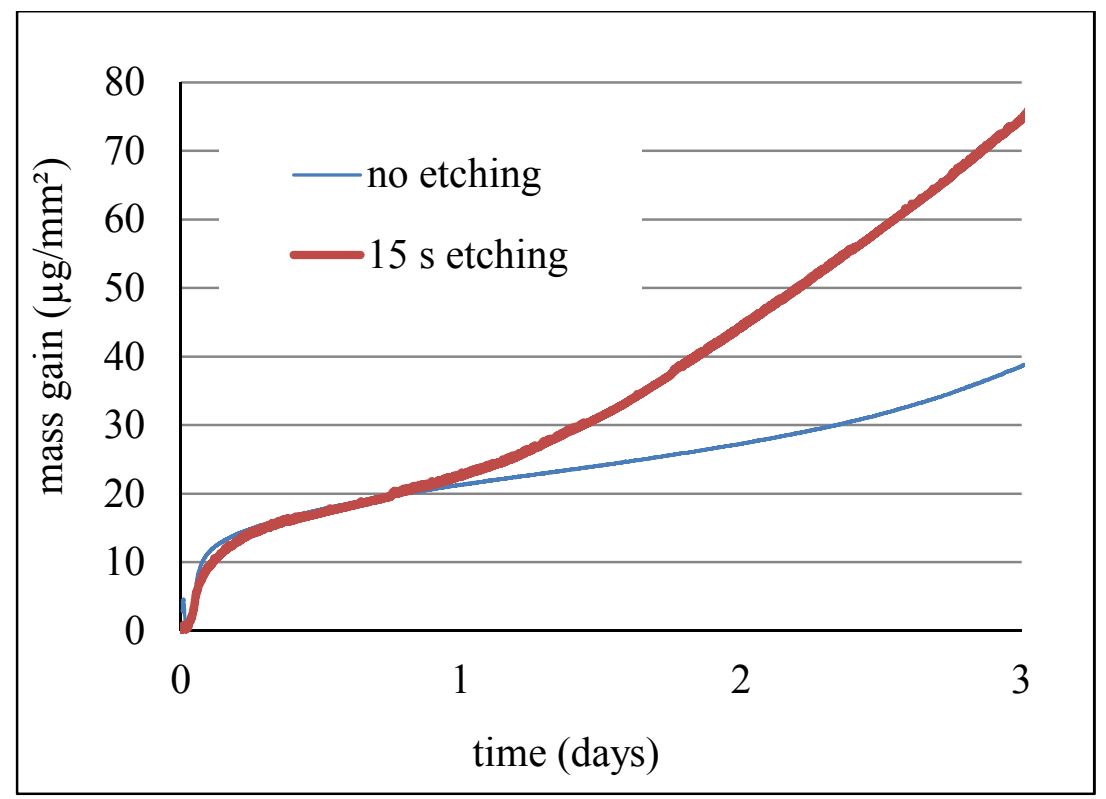

Figure 5. Influence of the etching on the mass gain of shot-peened samples for $10 \mathrm{~min}$.

In order to highlight the only role of the stress on the oxidation by avoiding the influence of the pollution of the surface we proceed to remove the superficial layers of the material of shot-peened samples by etching. The Fig. 6 presents the mass gain curve for two durations of shot-peening: 10 min and $30 \mathrm{~min}$. As for the un-etched samples, longer the shot-peening duration, smaller the mass gain during oxidation. This is the proof that the mechanical state introduced during the shot-peening process is the main factor, and not the pollution, for the slower oxidation rate of the samples.

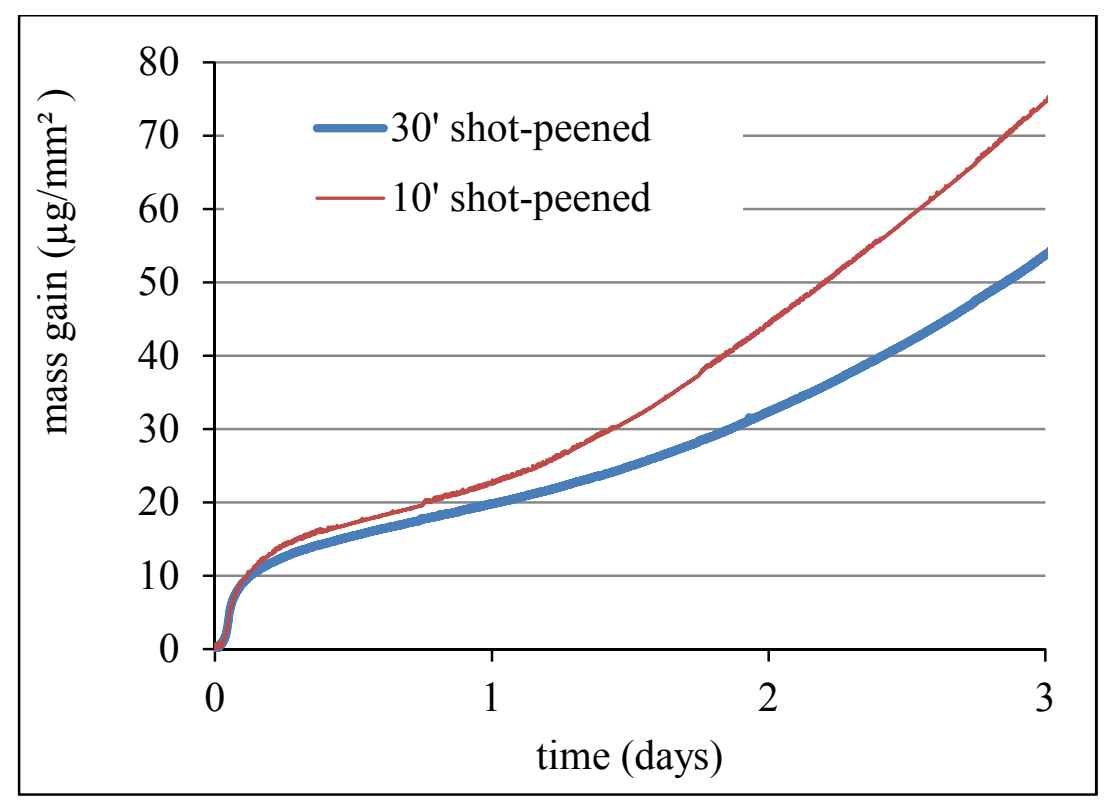

Figure 5. Influence of the shot-peened duration for etched samples .

\section{Summary}

The present works deal with the oxidation of shot-peened samples and investigate the influence of the main factors that can produce a slower oxidation of the shot-peened samples. We have shown that longer the shot-peening duration, smaller the oxidation rate. This is true as well either for etched or un-etched samples, proving that the slight surface pollution that occurs during the shotpeening is not responsible for the oxidation behavior. Annealing of the samples shows that when the 
stress state is annihilated the oxidation rate is sensibly bigger, which once gain highlight the role of the mechanical stress on the oxidation.

Several questions emerged after this study. One of these is why the etching does not modify the early steps of oxidation but affects the later stages? This will be one of the objects of our future research works.

\section{Acknowledgements}

The authors would like to thank the LASMIS laboratory members (UTT, France) for the shotpeening treatment of our $\mathrm{Zr}$ samples.

\section{References}

[1] L. Raceanu, V. Optasanu, T. Montesin, G. Montay, and M. Francois, "Shot-Peening of PreOxidized Plates of Zirconium: Influence of Residual Stress on Oxidation", Oxid. Met. 79 (2013) 135-145

[2] F. Larché and J. W. Cahn, A linear theory of the thermochemical equilibrium of solids under stress, Acta Met., 21 (1973) 1051-1063

[3] J. Favergeon, T. Montesin and G. Bertrand, Mechano-chemical aspects of high temperature oxidation: A mesoscopic model applied to zirconium alloys, Oxid. Met, 64 (2005) 25-279

[4] N. Creton, V. Optasanu, T. Montesin, S. Garruchet, L. Desgranges, A thermodynamic approach of the mechano-chemical coupling during the oxidation of uranium dioxide, Def. Diff. For, 289-292 (2009) 447-454

[5] N. Creton, V. Optasanu, S. Garruchet, L. Raceanu, T. Montesin, L. Desgranges, S. Dejardin, Internal Interface Strains Effects on UO2/U3O7 Oxidation Behaviour, Def. Diff. For, 297-301 (2010) 519-524

[6] L. Raceanu, V. Optasanu, T. Montesin, N. Creton, Pre-stressed Sub-surface Contribution on Bulk Diffusion in Metallic Solids, Def. Diff. For, 309-311 (2011) 149-154

[7] V. Optasanu, L. Raceanu, T. Montesin, Simulation of Metal/Oxide Interface Mobility: Effects of Mechanical Stresses on Geometrical Singularities, Def. Diff. For, 323-325 (2012) 109-114

[8] L. Desgranges, H. Plancher, M. Gamaléri, S. Micha, V. Optasanu, L. Raceanu, T. Montesin, N. Creton, Influence on the U3O7 domain structure on cracking during the oxidation of UO2, J. Nuc. Mat, 402 (2010) 167-172

[9] L. Raceanu, "Contribution à l'étude des interactions entre contraintes résiduelles et dissolution d'oxygène dans un solide déformable réactif", PhD Thesis, Université de Bourgogne (2011) 